properties of resistors made from various carbon blacks bonded with resins.

Methods of preparing dense, unreactive carbon are of great importance. If successful, they would find application both in bulk form and as surface coatings for less dense material. Recent work (A. R. G. Brown and W. Watt) shows that dense impervious material is produced by the thermal decomposition of hydrocarbons at a hot surface $\left(1,600-2,100^{\circ} \mathrm{C}\right.$.), and surface coatings of this kind enhance the chemical resistance of more reactive graphites. The kinetics of deposition of carbon films from benzene and toluene vapour carried by a stream of helium in a rather lower tem. perature range $\left(850-950^{\circ} \mathrm{C}\right.$.) have been studied by Kinney and Murphy.

Carbons as normally prepared may contain, besides small amounts of trace elements, a substantial amount of hydrogen, oxygen, nitrogen and sulphur. These elements may have an important influence on the structure, and Riley, Baraniecki and Streeter reviewed the properties of these 'heterocarbons'. The particular case of graphitic oxide has been studied extensively in the past thirty years : the present position was reviewed by de Boer and van Doorn in the light of their more recent work.

Considerable emphasis was placed on industrial carbon as a constructional material. Reviews of its applications in various industries were contributed by Lyddon and Hurden (mechanical engineering); K. F. Anderson (chemical engineering); H. D. Anderson and Ward (chemical plant); Hilliard (heat exchangers); Haines (high-temperature furnaces) ; G. E. Ross and D. W. Brown (metallurgy); Lakin and Mackenzie (blast-furnace linings). The mechanical properties relevant to these applications were discussed by H. W. Davidson, Losty and A. M. Ross, and by Arragon and Berthier, while methods of nondestructive testing were outlined by T. D. Davidson.

The most important new field of application of industrial graphite is in nuclear-power plant, where to the desirable properties of high density, low reactivity and mechanical strength, must be added the over-riding requirement of high purity. Discussions of this application and of the required properties were contributed by McIntosh, Heal and Cowen; Lockett; and McIntosh, O'Driscoll and Tyzack. Special attention has to be paid to the effects of high temperatures and of neutron irradiation, and papers by Hove and by Simmons were concerned with these problems. In studying the suitability of various raw materials and manufacturing procedures for nuclear-graphite production, large-scale experimental plant is needed, and that recently constructed at Harwell was described by Price and Yeats. The problems arising in the manufacture of nuclear graphite were discussed by Cornault and Rochettes. High purity may in principle be attained either by using very pure raw materials, by the purification of ordinary graphite or by purification in the course of the final graphitization. The latter method is that actually chosen, and a study of the purification of graphite by treatment with gaseous chlorine or a chlorofluorohydro. carbon during graphitization was the subject of a paper by Odening and Bowman. The resultant purity depends on the permeability of the carbon : the high density and low porosity desirable in graphite for use as a moderator may not be compatible with gas-purification methods. Methods of estimating the purity of reactor graphite were mentioned in several papers-the usual method being to compare the effect of different graphites on the time required for the reactor to become critical ; detection and estimation of rare earths by the radioactivation technique and a study of the changes of rare earth content in the course of graphite manufacture was described by Decour, Leveque, Hering and Jouquet. The alteration of properties brought about by purification was discussed by Baroin.

During the period of the Conference an exhibition of industrial carbon and graphite was held in the Department of Chemical Engineering, University College, London; and this, together with several social functions, contributed to the success of the Conference.
D. H. EveretT

\title{
SAFETY IN MINES RESEARCH
}

$\mathrm{T}$ HE scope of the Safety in Mines Reserch Advisory Board was widened early in 1956 when the Board was re-appointed, with Prof. R. V. Jones as chairman, and given new terms of reference which ask the Board "to keep under review and advise the Minister of Power on the general scope, organization and progress of research work on safety in mines". Until then the scope had been restricted to the Ministry's research work on the subject. It is appropriate, therefore, for the thirty-fifth annuel report on safety in mines research (London : H.M. Stationery Office, 1958) to include a short account of the ninth international conference of directors of safety in mines research and to give in appendixes not only synopses of recent publications of the Safety in Mines Research Establishment, but also a list of papers presented by all the delegates to the ninth international conference.

The report, however, is essentially a report of the work of the Safety in Mines Research Establishment for the yeur 1956. During the year the move to new premises, in Broad Street, Sheffield, housing the engineering sections and much of the Technical Information Service Department, was begun. It is significant that the acute problem of accommodation has resulted "as much from increasing the strength of research teams to the necessary extent, as from the increasing complexity of the work". As the director of the Establishment, Mr. H. T. Ramsay, remarks in his introduction to the report, "Mining research has been in progress for a long time and the essier answers have usually been found; real advances against the remaining hazarda will only be made by a penetrating study of their mechanisms and, so far from becoming easier, one may expect the Establishment's work to become more difficult".

Most of the report is concermed with the research of the Establishment into the hazards of mining. 'There are eight main sections, nomely, explosives and blasting devices, the explosion hazard, breathing apparatus, fire hazard, engineering and metallurgical research, dust control and pneumoconiosis hazard, 
miscellaneous, and testing services. The wide scope of the work of the establishment is illustrated by the fact that within the eight main sections there are nearly a hundred sub-sections dealing with such widely different topics as pulsed infusion of coal, ignition of gases by sparks of various origins, fighting roadway fires with foam-plugs, atomic hydrogen welding of wrought iron, catalytic oxidation of exhaust gases of Diesel locomotives, deposition and dispersion of respirable dust, automatic assessment of miners' pneumoconiosis from chest radiographs, safety helmets and factors affecting the movement and control of rats in drift mines.

It is not easy to select from the necessarily highly condensed accounts of investigations included in the report examples which illustrate adequately the scope and quality of the work of the Establishment ; accordingly, the largest sections, those devoted to the explosion hazard and to engineering and metallurgical research, are selected for mention. The report points out that, during the decade 1946-55, there was a marked decrease in the number of casualties from explosions in mines in Great Britain, due not to any great reduction in the number of gas ignitions but to reduced severity of the explosions as measured by the number of casualties. This improvement may well be due to improved mine ventilation and gas control, with consequent reduction in the size of accumulations of gas available for inflammation. It is felt by the Establishment that current research on the causes of ignition of gas in mines should be supplemented by research on the movement of firedamp in mines and on the dispersal of accumulations of gas. Coal-dust explosions in mines are generally initiated by explosions of methane, so that attention continues to be directed towards the ignition of methane, particularly by frictional sparking such as may occur when certain light alloys striko rusty steel, or from steel chock releases, or from auger mining, or from rocks during drilling.

So far as coal-dust explosions are concerned, the report includes work on binding of coal dust by dilute solutions of adhesive and by aerosols, and work in the Establishment's explosion gallery at Buxton on the propagation and prevention of propagation of a coal-dust explosion. The work in the gallery includes an investigation on the dispersion of dust by, and in, the blast from an explosion. An interesting part of that section on explosions deals with the application of gas chromatography followed by a hot-wire detector (or for some purposes an infra-red analyser) for analysis of mine atmospheres, natural gases from boreholes in coal and ironstone mines, fire products and Diesel exhausts.

The section on engineering and metallurgical research shows that light-weight roof-bars were studied during 1956 especially in respect of their stability in temporary support systems at roadheads. Attention was given to the development of convenient and rapid non-destructive methods for checking the soundness of welds in chain links, of particular importance, for example, in cage suspensions. Several failures in ropes and components of couplings and draw gear were examined, and as a result theoretical and experimental work was begun to find improvements in design or in choice of material; photoelastic methods are being used increasingly in this work. Mining gear may be subjected to corrosion arising from, for example, moist salt spread in mines to bind dust, from acid pit-water, or from the reaction products between salt and acid pit-water. The effects of potentially corrosive materials on mining gear, including wire ropes, were examined during the year and the influence of certain inhibitors was investigated.

As mentioned above, it is not easy to deal adequately in this short notice with the wide variety of work summarized in the report. The report will be read, as the earlier reports of the Establishment have been, with real interest by those connected with the mining industry. It can be recommended, also, to those who are not connected with the mining industry, not only because of the wide range of problems receiving attention but also because several of the problems are similar to those found in other industries.

\section{BIOLOGISTS IN THE TROPICS}

$\mathrm{O}^{\mathrm{N}}$ July 5 a meeting was arranged by the Institute of Biology to discuss the professional problems of biologists serving overseas. A report of the meeting has been published in the Institute's Journal (4, No. $4 ; 1957)$. The meeting was opened by Dr. Kenneth Mollanby, lately principal of the University College, Ibadan, Nigeria, who said that many of the economic problems of tropical territories could only be solved by biologists, for whom there are an immense number of fascinating and important problems waiting to be tackled. So far, there has been very little serious biological research in any part of the tropics. Hard-pressed government officials in a number of territories have done much fine work, but shortages of staff and the constant preoccupation with ad hoc measures have meant that the fundamental work on which practical measures should be based has not been tackled. At times, the need for such fundamental work has not even been realized; in Nigeria the belief was that there was no need for any work on cocoa and its pests because this was all covered by the work of the Cocoa Research Station in Ghana. There are many more entomologists in Britain studying the wheat bulb fly than there are in West Africa concerned with the pests of cocoa, the mainstay of the economy of Ghana and Western Nigeria.

Dr. E. E. Weatherly, who some years ago worked as a botanist in the Department of Agriculture, Uganda, indicated that there could be no better experience for a biologist of Ph.D. level than that of spending a few years of research in a tropical country. The major professional difficulty in working in tropical parts is that of isolation. First, there is isolation from libraries. To a scientist the library comes second only to the laboratory, but a library is more difficult and expensive to equip and maintain than a laboratory. This difficulty is inherent in spreading out research over isolated and remote stations, for even reasonably useful libraries simply cannot be maintained at such centres.

Next to the absence of books comes the absence of professional colleagues. Except for the very few, 